\title{
Decomposition of Dithiocarbamates. V.1) The Dissociations of N-Monosubstituted Dithiocarbamic Acids in strongly Acidic and Alkaline Solutions
}

\author{
Fumitaka Takami, Kanji Tokuyama, Shigeru Wakahara, \\ and TAKashi MAEDA
}

Shionogi Research Laboratory, Shionogi \& Co., Ltd.2)

(Received July 29, 1972)

\begin{abstract}
The dissociations of five $\mathrm{N}$-monosubstituted dithiocarbamic acids (I) in strongly acidic and alkaline solutions were investigated spectrophotometrically. The existence $K_{\mathrm{I}} K_{\mathrm{II}} K_{\text {III }}$ of following equilibrium, IV those dissociation constants were determined. The Bronsted correlations between $\mathrm{p} K^{\prime}{ }_{\mathrm{I}}$ or $\mathrm{p} K^{\prime}{ }_{\text {III }}$ and $\mathrm{p} K \mathrm{a}$ of corresponding amines $\left(\mathrm{p} K_{\mathrm{N}}\right)$ were found; $\mathrm{p} K_{\mathrm{I}}^{\prime}$ or $\mathrm{p} K^{\prime}{ }_{\mathrm{III}}=0.48 \mathrm{p} K_{\mathrm{N}}+$ $\alpha\left(\alpha=-9.06\right.$ for $\mathrm{p} K^{\prime}{ }_{\mathrm{I}}$; eq. 7 , and $\alpha=12.43$ for $\mathrm{p} K^{\prime}{ }_{\mathrm{III}}$; eq. 8$)$.
\end{abstract}

Dithiocarbamic acids are well known to have important uses as fungicides, chelating agents, vulcanization accelerators and synthetic intermediates for heterocyclic compounds. ${ }^{\mathbf{3}}$ ) Most of papers have dealt solely with the properties of N,N-disubstituted dithiocarbamic acids. ${ }^{4)}$ On the other hand, reliable papers have scarcely been presented on the properties of N-monosubstituted dithiocarbamic acid (I), ${ }^{\mathbf{4}, 5)}$ though $\mathrm{I}$ is especially important as synthetic intermediates such as [(4-amino-2-methyl-5-pyrimidinyl)methyl]dithiocarbamic acid (Id) for thiamine production. ${ }^{6}$

It has long been known that I decomposes by three different modes (see Chart 1). One is the decomposition to corresponding amine and carbon disulfide (Reaction A). ${ }^{\text {5) }}$ It occurs predominantly in acidic solutions and proceeds via a fast proton pre-equilibration between

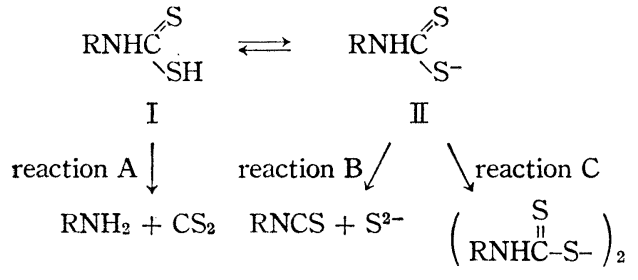

Chart 1

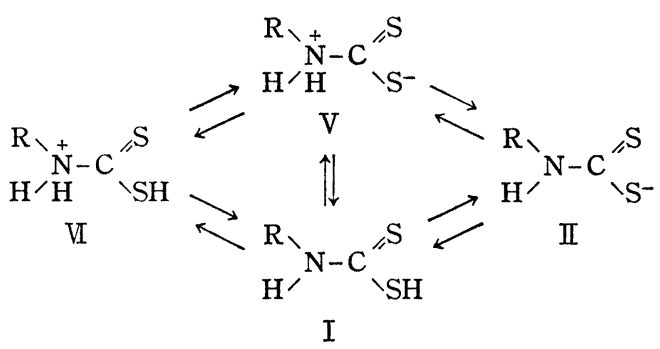

Chart 2

1) a) For part IV. See F. Takami, S. Wakahara, and T. Maeda, Chem. Lett., 1972, 409. A part of this paper was reported in a preliminary form: F. Takami, S. Wakahara, and T. Maeda, Tetrahedron Letters, 1971, 2645; b) Pyrimidines part XIII. For part XII, see T. Nishino, M. Kiyokawa, Y. Miichi, and K. Tokuyama, Bull. Chem. Soc. Japan, 46, 580 (1973).

2) Location: Fukushima-ku, Osaka, 553, Japan.

3) G.D. Thorn and R.A. Ludwig, "The Dithiocarbamates and Related Compounds," Elsevier, New York, 1962.

4) D.J. Halls, Mikrochim. Acta, 1969, 62 .

5) a) S.J. Joris, K.I. Aspila, and C.L. Chakrabarti, Anal. Chem., 41, 1441 (1969); Idem, J. Phys. Chem., 74, 860, 3625 (1970); R.R. Vandebeek, S.J. Joris, K.I. Aspila, and C.L. Chakrabarti, Can. J. Chem., 48, 2204 (1970); b) D.M. Miller and R.A. Latimer, ibid., 40, 246 (1962).

6) K. Sumi, Yakugaku Zasshi, 66A, 62 (1946); M. Tomita, S. Uyeo, H. Inoue, H. Sakurai, and S. Moriguchi, ibid., 68, 151 (1948); T. Matsukawa and T. Iwatsu, ibid., 69, 550 (1949); 70, 28 (1950). 
the acid form I and the anion form II followed by a subsequent decomposition of the species I to the amine and carbon disulfide. ${ }^{5,7}$ The others are the formations of isothiocyanates (Reaction B) ${ }^{4,8}$ and thiuramdisulfides (Reaction C). ${ }^{4,7}$ They are reported to occur in alkaline solutions, but mechanisms are not unequivocally established.

The preference of the above Reactions, A, B, and C, seemed to be ascribed to that of the equilibrium among possible forms of I in solutions. Zahradnik and Zuman initially suggested the possibility of the equilibria as shown in Chart $2 .{ }^{91}$

The presence of I and II has been established from kinetic studies of the Reaction $A$, but that of $\mathrm{V}$ was excluded.5) The protonation form of I, (IV) or (VI), can also exist since I has the two potential protonation sites, $\mathrm{S}$ and $\mathrm{N}$. Another equilibrium should exist between II and it's conjugate base (III). Thence, the possible entire dissociation scheme of I can be dipicted as shown in Chart 3.

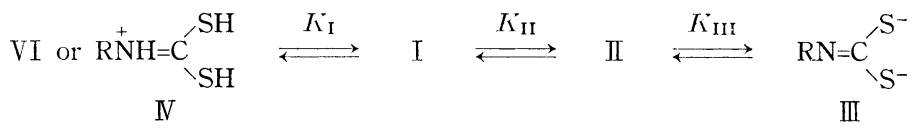

Chart 3

It is an important problem to determine the above dissociation scheme and their dissociation constants exactly for understanding of the Reactions, A, B, and C.

The present paper refers to the values of $K_{\text {I }}^{\prime}$ and $K_{\text {III }}^{\prime}$ of methyl (Ia), ethyl (Ib), benzy] (Ic) and phenyldithiocarbamic acids (Ie) and Id.

\section{Experimental}

Materials - The sodium salts of I, except Id, were synthesized by the methods appeared in literatures. ${ }^{10)}$ The compound Id was obtained as the inner salt. ${ }^{11)}$ Methyl methyldithiocarbamate (VII) and dimethyl methylimidodithiocarbamate (VIII) were prepared by the usual methods. ${ }^{12}$ ) All reagents were of reagent grade and distilled water was used throughout the experiments.

Apparatus_- A Hitachi two wave length/double beam spectrophotometer, model 356, was used to study the ultrariolet (UV) spectra. A quartz cell of $10 \mathrm{~mm}$ path length was used. Temperature was maintained at $25 \pm 0.1^{\circ}$ by circulating water from a Haake thermostat through the cell jacket.

Methods-a) UV Spectral Measurements: The UV spectra in strongly acidic and allsaline solutions were observed at $25^{\circ}$. The solution of $5 \times 10^{-3} \mathrm{M}$ of $\mathrm{I}$ in $0.01 \mathrm{~N} \mathrm{NaOH}$ was diluted with 100 volumes of sulfuric acils or with those of caustic alkalis of appropriate concentrations. Used acidic and alkaline solutions were previously deairated by nitrogen stream. The spectral measurements of I in sulfuric acid solutions were performed as soon as possible after the dilution to 100 times, because I decomposes slowly.

b) Confirmation of the Reversibilities of $\mathrm{I} \rightleftharpoons \mathrm{IV}$ or VI and of II $\rightleftharpoons$ III: When the spectra of $5 \times 10^{-4} \mathrm{M}$ solution of I in strongly acidic solutions was measured in a short-path cell of $1 \mathrm{~mm}$, one peak of IV or VI appeared. Regeneration of the two peaks of I was observed after dilution with 10 volumes of water in a standard cell of $10 \mathrm{~mm}$ length. The reversibility of $\mathrm{II} \rightleftharpoons \mathrm{III}$ in alkaline solutions was also confirmed in a way similar to the above.

c) $\mathrm{p} K \mathrm{a}$ Determination: The $\mathrm{p} K^{\prime}{ }_{\mathrm{is}}$ of $\mathrm{Ia}-\mathrm{d}$ were determined spectrophotometrically at a constant wavelength of $260-270 \mathrm{~nm}$ regions by using $10-80 \%$ sulfuric acids. Since these compounds decompose slowly, the absorbance was extrapolated to zero time. The data were treated by the least-squares method for eq. 5. The absorbance of un-ionized form was determined by using $10 \%$ sulfuric acid solutions.

The $\mathrm{p} K_{\text {IIIS }}^{\prime}$ of $\mathrm{Ia}-\mathrm{e}$ were determined by using the changes at a constant wavelength of $280-290 \mathrm{um}$. The absorbance of I showed no change for the period of measurement. The absorbance of un-ionized form

7) S.J. Joris, K.I. Aspila, and C.L. Chakrabarti, Anal. Chem., 42, 647 (1970).

8) M. Wroński, Zeszyty Nauk. Uniw. Lódz., Nauki Mat.-Przyrod. Ser. II, No. 6, 121 (1959) [C.A., 55, 4113 (1961)].

9) R. Zahradnik and P. Zuman, Chem. Listy, 52, 231 (1958).

10) H.L. Klöpping and G.J. Van Der Kerk, Rec. Trav. Chem., 70, 917 (1951); D.J. Halls, A. Townshend, and P. Zuman, Anal. Chim. Acta, 40, 459 (1968).

11) A. Takamizawa, Y. Sato, S. Nakajima, and T. Ishiba, Shionogi Kenkyusho Nempo, 12, 48 (1962).

12) Y. Ueno, T. Nakai, and M. Okawara, Bull. Chem. Soc. Japan, 44, 1933 (1971). 
was determined by using $1 \times 10^{-2} \mathrm{~N}$ of alkaline solution and the data of $1 \times 10^{-2}$ to $15 \mathrm{~N}$ of akaline solutions were treated by eq. 3 in a manner similar to those in acicl solutions.

\section{Result and Discussion}

\section{Dissociation Constants $\left(\boldsymbol{K}^{\prime}{ }_{\text {III }}\right)$ in strongly Alkaline Solutions}

Dithiocarbamic acid I shows two absorption bands near at 250 and $280 \mathrm{~nm}$ of fairly high intensity $(\log \varepsilon=4)$ in weakly alkaline solutions as reported previously ${ }^{3,4}$ ) (see Table I). The UV spectra of Ia at 248 and $281 \mathrm{~nm}$ in weakly alkaline solutions changed greatly in strongly alkaline solutions $(8-15 \mathrm{~N} \mathrm{KOH})$. The intensity of the longer wavelength decreased with the increase of alkaline concentration, while that of the shorter wavelength increased. A selection of absorption curves is recorded in Fig. 1. The spectra showed an isosbestic point at $267 \mathrm{~nm}$. The absorption peak at $281 \mathrm{~nm}$ once disappeared in $15 \mathrm{~N} \mathrm{KOH}$ solution reappeared by the dilution with water. These spectral changes should be due to the shift of the equilibrium between II and it's conjugate base III from left to right:

$$
\mathrm{II} \stackrel{K_{\mathrm{III}}^{\prime}}{\rightleftarrows} \mathrm{III}+\mathrm{H}^{+}
$$

The existence of the equilibrium is obvious since I was isolated as III when I has electronattractive substituent, e.g., $\mathrm{R}=\mathrm{CN}^{13)}$ or $\mathrm{R}^{\prime} \mathrm{SO}_{2} \cdot{ }^{14}$ ) Further evidence can be provided by the fact that the spectral changes between IIa $\left(\lambda_{\max }^{0.1 \mathrm{~N} \text { NaOH }} 248,281 \mathrm{~nm}\right)$ and IIIa $\left(\lambda_{\text {max }}^{\text {15N KoH }}\right.$ $246 \mathrm{~nm})$ correspond to those between methyl methyldithiocarbamate (VII) $\left(\lambda_{\max }^{\mathrm{H} O} 245,267 \mathrm{~nm}\right)$ and dimethyl methylimidodithiocarbamate (VIII) $\left(\lambda_{\max }^{\mathrm{H} O \mathrm{O}} 238 \mathrm{~nm}\right)$.

The value of $K_{\text {III }}^{\prime}$ was successfully determined by using the eq. $2 ; 15$ )

$$
h_{\mathrm{III}}^{\prime \prime}=(\mathrm{III})\left(\mathrm{H}^{+}\right) /(\mathrm{II})=\left(\mathrm{E}_{\mathrm{II}}-\mathrm{E}\right)\left(\mathrm{H}^{+}\right) /\left(\mathrm{E}-\mathrm{E}_{\mathrm{III}}\right)
$$

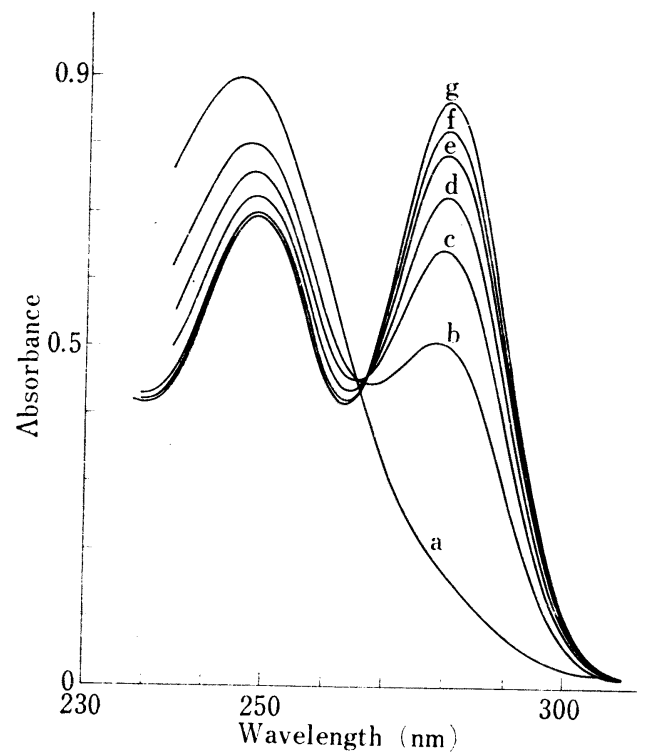

Fig. 1. Absorption Spectra of Ia in Alkali at $25^{\circ}:$ a: $15.0 \mathrm{~N} ; \mathrm{b}: 12.0 \mathrm{~N} ; \mathrm{c}: 11.0 \mathrm{~N} ; \mathrm{d}$ : $10.0 \mathrm{~N} ;$ e: $9.0 \mathrm{~N} ; \mathrm{f}: 8.0 \mathrm{~N} ; \mathrm{g}: 5.0 \mathrm{~N} \mathrm{KOH}$

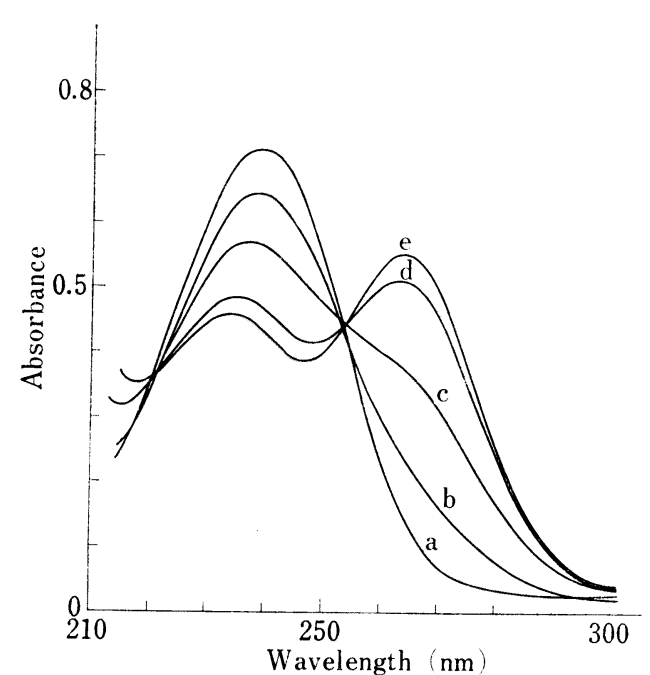

Fig. 2. Absorption Spectra of Ia in Sulfuric Acid at $25^{\circ}$ : a: $68.6 \%$; b: $58.7 \%$; c: $54.9 \%$; d: $48.6 \%$; e: $39.3 \% \mathrm{H}_{2} \mathrm{SO}_{4}$

13) A. Hantzsch and M. Wolvekamp, Ann. Chem., 331, 265 (1904); W.A. Thalen and J.R. Divitt, J. Org. Chem., 36, 14 (1971).

14) R. Gompper and W. Hängele, Chem. Ber., 99, 2885 (1966).

15) L.A. Flexser, L.P. Hammett, and A. Dingwall, J. Am. Chom. Soc., 57, 2103 (1935). 
where $\mathrm{E}_{\mathrm{II}}, \mathrm{E}_{\mathrm{III}}$, and $\mathrm{E}$ stand for the absorbance of II, III, and a mixture of II and III, respectively. An alternative eq. 3 enables us to calculate $K^{\prime}{ }_{1 I I}$ values, with or without knowing of $\mathrm{E}_{\mathrm{III}}$, by replacing $\left(\mathrm{H}^{+}\right)$with the non-logarithmic acidity function $h_{-.}{ }^{16}$ ) From the slope of the plots between $\mathrm{E}$ and $\left(\mathrm{E}_{\mathrm{II}}-\mathrm{E}\right) h_{-}, K^{\prime}{ }_{\mathrm{III}}$ of I was calculated by the least-squares method.

$$
\mathrm{E}=\left(\mathrm{E}_{\mathrm{II}}-\mathrm{E}\right) h_{-} / K_{\mathrm{III}}^{\prime}+\mathrm{E}_{\mathrm{III}}
$$

The values of $\mathrm{p} K^{\prime}{ }_{\text {III }}$ of Ia-e listed in Table II were obtained.

\section{Dissociation Constants $\left(K_{I}^{\prime}\right)$ in strongly Acidic Solutions}

The spectra of IIa are known to shift to shorter wavelength at 234 and $265 \mathrm{~nm}$ on the acidification of basic medium. ${ }^{5 b}$ ) These two peaks are unaltered in the range between $0.1-$ $6 \mathrm{~N} \mathrm{HCl}$. In more strongly acidic media, the protonation of the acid form I was expected to lead to the change of the spectrum. Thus, the spectra in $10-70 \%$ sulfuric acid solutions were measured. No appreciable changes were found in the solutions containing between 10 and $40 \%$ sulfuric acid solutions. In more concentrated solutions, however, the intensity of the band at longer wavelength decreased and that of shorter one increased with the increase of acid concentrations, as shown in Fig. 2.

The characteristic hypsochromic shift to a single peak indicates the presence of the chromophore $\mathrm{N}=\mathrm{C}<\mathrm{S}$ in the conjugate acid of I as in III (see Table II). Thence, the conjugate acid was identified as IV.

The overwhelming protonation to give rise to IV can be explained by molecular orbital calculation by which the net charge $(Q)$ of the thiocarbonyl-sulfur atom is more negative than that of nitrogen atom. ${ }^{17}$ ) The $\mathrm{N}$-protonated form VI must be unfavorable because of the lacking of the stabilization by resonance. The evidence for the protonation on thiocarbonyl-sulfur atom is further supported by the studies on the protonation at the carbonyloxygen for amides ${ }^{18)}$ and carbamic acids. ${ }^{19}$ )

Accordingly, the values of $K_{I}^{\prime}$ were calculated from the slope of the plots of eq. 5 , where $h_{0}$ is the Hammett's non-logarithmic acidity function..$^{20)}$

$$
\mathrm{E}=\left(\mathrm{E}_{\mathrm{I}}-\mathrm{E}\right) h_{0} / K_{\mathrm{I}}^{\prime}+\mathrm{E}_{\mathrm{IV}}
$$

(eq. 5)

\begin{tabular}{|c|c|c|c|c|c|}
\hline \multirow{2}{*}{ Compound } & \multicolumn{5}{|c|}{$\lambda_{\max } \mathrm{nm}(\log \varepsilon)$} \\
\hline & \multicolumn{2}{|c|}{$0.1 \mathrm{~N} \mathrm{NaOH}$} & \multirow{2}{*}{$\frac{15 \mathrm{NOH}}{246(4.18)}$} & \multirow{2}{*}{$\frac{0.1 \mathrm{~N} \mathrm{HCl}}{233(3.90), 265(4.06)}$} & \multirow{2}{*}{$\frac{80 \% \mathrm{H}_{2} \mathrm{SO}_{4}}{242(4.02)}$} \\
\hline Ia & $248(4.06)$ & $281(4.15)$ & & & \\
\hline $\mathrm{Ib}$ & $251(4.08)$ & $282(4.16)$ & $248(4.16)$ & $235(3.92), 267(4.06)$ & $243(4.05)$ \\
\hline Ic & $253(4.16)$ & $285(4.18)$ & $249(4.23)$ & $237(4.06), 270(4.07)$ & $244(4.09)$ \\
\hline $\mathrm{Id}$ & $\begin{array}{l}\left.233(4.18),{ }^{a}\right) \\
285(4.29)\end{array}$ & $253(4.16)$ & $249(4.34)$ & $243(4.32), 257(\mathrm{sh})(4.24)$ & $243(4.37)^{b)}$ \\
\hline $\mathrm{Ie}$ & $257(3.99)$ & $291(4.26)$ & $260(4.20)$ & c) & $\begin{array}{l}253(4.07), \\
273(\mathrm{sh})(3.79)^{b)}\end{array}$ \\
\hline
\end{tabular}

TABLE I. UV Spectra of Dithiocarbamic Acids (I)

a) The peak due to the pyrimidine nucleus.

b) in conc. $\mathrm{H}_{2} \mathrm{SO}_{4}$

c) could not be obtained because of the rapid decomposition

16) G. Yagil, J. Phys. Chem., 71, 1034 (1967).

17) M.J. Janssen, Rec. Trav. Chim., 79, 1006 (1960); Y. Ozias and L. Reynard, Theoret. Chim. Acta (Berl.), 20, 51 (1971).

18) C. O'Connor, Quart. Rev., 24, 533 (1970).

19) G.A. Olah and M. Calin, J. Am. Chem. Soc., 90, 401 (1968).

20) M.A. Paul and F.A. Long, Chem. Rev., 57, 1 (1957). 
The absorbance of the solution was measured by extrapolating to the time of mixing since the slow decomposition was accompanied inevitably. The $\mathrm{p} K_{\mathrm{I}}^{\prime}$ values of Ia-d were obtained and listed in Table II. The $\mathrm{p}{K^{\prime}}_{\mathrm{I}}$ measurement of Ie was failed because of it's rapid decomposition.

TABLE II. Dissociation Constants of Dithiocarbamic Acids I at $25^{\circ}$

\begin{tabular}{ccccl}
\hline Compound & $\begin{array}{c}\mathrm{p} K_{\mathrm{a}} \text { of corresponding } \\
\text { amine }\left(\mathrm{p} K_{\mathrm{N}}\right)\end{array}$ & $\mathrm{p} K_{\mathrm{I}}^{\prime}$ & $\mathrm{p} K^{\prime}{ }_{\mathrm{II}}$ & $\mathrm{p} K^{\prime}{ }_{\mathrm{III}}$ \\
\hline Ia & $10.67^{a)}$ & -3.9 & $2.89^{b)}$ & 17.6 \\
Ib & $10.70^{a)}$ & -4.1 & $3.05^{c)}$ & $17.6\left[13.2\left(70^{\circ}\right)\right]^{d)}$ \\
Ic & $9.35^{a)}$ & -4.5 & & $16.9,17.1$ \\
Id & $8.24^{e)}$ & -5.2 & & $16.2,16.4,16.5$ \\
Ie & $4.60^{a)}$ & - & & $14.6,14.6,14.8\left[13.3\left(45^{\circ}\right)\right]^{e)}$ \\
\hline
\end{tabular}

a) D.D. Perrin, "Dissociation Constants of Organic Bases in Aqueous Solution," Butherworths; London, 1965 $\left.\begin{array}{llll}b) & \text { data in Ref. } 7 & c\end{array}\right)$ data in Ref. $5 \mathrm{~b} \quad l$ ) data in Ref. $8 \quad e$ ) S. Mizukami and E. Hirai, Chem. Pharm. Bull. (Tokyo), 14, 1321 (1966)

On the basis of the above results the entire dissociation scheme of $\mathrm{I}$ is concluded as shown in eq. 6 .

$$
\text { IV } \stackrel{K_{\mathrm{I}}}{\rightleftarrows} \mathrm{I} \stackrel{K_{\mathrm{II}}}{\rightleftarrows} \text { II } \stackrel{K_{\mathrm{III}}}{\rightleftarrows} \text { III }
$$

The values of $\mathrm{p} K^{\prime}{ }_{\mathrm{I}}$ and $\mathrm{p} K^{\prime}{ }_{\text {III }}$ (see Table II) decrease with the decrease of electron-donatng charactor of the N-substituents. Such $\mathrm{pKa}$ values are correlated with Hammett's $\sigma$ values but there are no available data for the $\sigma$ value of (4-amino-2-methyl-5-pyrimidinyl)methyl moiety. Figure 3 leads to the empirical relationships between $\mathrm{p} K^{\prime}{ }_{\mathrm{I}}$ (eq. 7 ) or $\mathrm{p} K^{\prime}{ }_{\text {III }}$ of $\mathrm{I}$ (eq. 8) and $\mathrm{p} K \mathrm{a}$ of the corresponding amines $\left(\mathrm{p} K_{\mathrm{N}}\right)$.

$$
\begin{aligned}
& \mathrm{p} K_{\mathrm{I}}^{\prime}=0.48 \mathrm{p} K_{\mathrm{N}}-9.06 \\
& \mathrm{p} K_{\mathrm{III}}^{\prime}=0.48 \mathrm{p} K_{\mathrm{N}}+12.43
\end{aligned}
$$

The equations suggest that the substituent effects respond to the same degree to $\mathrm{p} K_{\mathrm{I}}{ }^{\prime}$ and $\mathrm{p} K^{\prime}{ }_{\text {III }}$. Thus the eq. 9 is obtained from the sets of eqs. 7 and 8 . These relationships indicate that the electron-donating substituents on nitrogen atom cause the increases of the electron density on the nitrogen and sulfur atoms.

$$
\mathrm{p} K_{\mathrm{I}}^{\prime}=\mathrm{p} K_{\mathrm{III}}^{\prime}-21.49
$$

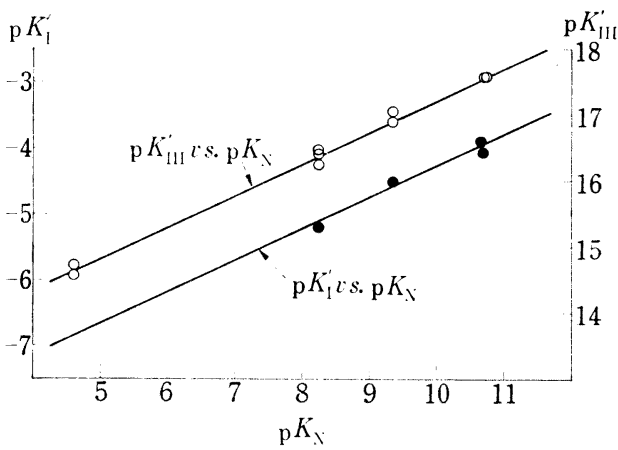

Fig. 3. Bronsted Plots of $\mathrm{p} K_{1}^{\prime}$ and $\mathrm{p} K^{\prime}{ }_{\mathrm{III}}$ against $\mathrm{p} K_{\mathrm{N}}$ of Amine

Similarly, the electron-donating group should decrease the polarity of the S-H bond of I. The value of $\mathrm{pK}_{\mathrm{II}}^{\prime}$ is expected to increase with the increase of the electron-donating character of the $\mathrm{N}$-substituent. Under the assumption that the substituent effects for $\mathrm{p} K^{\prime}$ II are same with those for $\mathrm{p} K^{\prime}{ }_{\mathrm{I}}$ and $\mathrm{p} K^{\prime}{ }_{\text {III }}$, the equation 10 can be proposed by using the only reliable value, 2.89 for Ia, reported.7) The reliability of this equation will be presented separately.

$$
\mathrm{p} K_{1 \mathrm{I}}^{\prime}=0.48 \mathrm{p} K_{\mathrm{N}}-2.23
$$

It is of interest to compare $\mathrm{p} K_{\text {III }}^{\prime}$ values of the present work to those of Wronski, obtained by kinetic studies; 13.2 for Ib and 13.3 for Ie. ${ }^{8)}$ It has been found that a great difference exists between them. It may be that there are some questions in his proposed pathway 
for the reaction $\mathrm{B}$. We are now investigating the Reaction $\mathrm{B}$ kinetically to determine an unequivocal reaction pathway.

Acknowledgement We are grateful to Professor Y. Inubushi, University of Kyoto, who has read and criticized the manuscript. We also thank Dr. K. Ikawa, Assistant Manager of the Production Department of this company, for his interest. 